\title{
DIREITO ADMINISTRATIVO - IMPORTÂNCIA E NECESSIDADE DO SEU ESTUDO
}

\author{
Consel heiro Montezuma
}

\begin{abstract}
SUMARIO : Importância do estudo do Direito Administrativo Direito Privado e Direito Público - A Constituição e as leis ordinárias - O Poder executivo - Administração discricionária Hieràrquia administrativa - A criação da cátedra de Direito Administrativo.
\end{abstract}

O Conselheiro Francisco Gê ACAIABa de Montezuma, cujo trabalho aqui se publica, foi jurista eminente. Nascido na Bahia em 23 de março de 1794, formou-se em Coimbra. Foi deputado à Assembléia Constituinte de 1823, de onde saiu para o exilio. Foi mais tarde Ministro da Justiça e Ministro Plenipotenciário na Inglaterra. Conselheiro de Estado. Senador. Advogado, foi um dos fundadores e primeiro Presidente do Instituto das Advogados.

Foi certamente no trato com os negócios públicos que encontrou inspiração para o fivernso pre foi encontrada no Tome $U$ (janeiro a março de 1869) da "Revista do Instituto da Ordem dos Advogados".

O trabalho tem o seu valor doutrinário e político, e tanto maior se considerarmos que, até então, poucos se haviam interessado pela criação da Cadeira de Direito Administrativo nos cursos jurídicos do país.

A primeira sugestão, ao que sabemos, coube ao Ministro Nicolau de CAMPOS VERGUeIRo, em 1833; mas a cadeira só foi criada em 1855. De sorte que Montezuma pode ser cansiderado um dos precursores da idéia.

O seu discurso obedece ao estilo da época - as doutrinas, os conceitcs, as concepçóes politicas são tiradas nos autores franceses. De GERANDo, LAFERRIERE, CoRMENIN, FouCART, MACAREL, etc. Nem, mesmo, no direito português encontraria mestres sôbre a matéria.

Mas, apesar disso, as suas concepçóes têm a largueza de uma visão politica esclarecida e a experiência bebida na oposição política e na prática administrativa.

$E^{\prime}$, por isso mesmo, trabalho que deve ser lido e meditado, o que a ota nota se segue. $-T, B . C$. 


\section{* Omissis.}

Senhores, não é meu fim fazer uma oração laudatória da instrução em geral; e menos ainda chamar a atenção da autoridade suprema para a estrita obrigação, em que está, de promover a educação intelectual do povo. Senhores, se o Brasil não é um dos países onde maior cota da renda nacional e provincial é consignada para a instrução pública; se o seu govêrno não é um dos que se ocupam com maicr solicitude da mais nobre das necessidades da nossa natureza moral; se tanto quanto pode não promove a educaçā intelectual, de acôrdo com a moral, e religiosa do povo, receando menos ser excessivo, do que mesquinho, em objeto de tamanha transcendência, e pública utilidade; se tanto quanto pode, e the cabe, não vela tais estabelecimentos; pelo menos é certo que, prudentemente, se vigia de todos os abusos, e exagerações, que soem ocasionar, não direi perseguição, mas vexame, desânimo, que é sempre fatal à cultura do entendimento, que ama ver-se em razoada liberdade; e considerando o ensino público uma verdadeira necessidade nacional, elevando o magistério à dignidade de uma espécie de sacerdócio, e animando por meio de privilégios importantes os que procuram instruir-se, e frequientam as escolas públicas, ou particulares, têm mostrado os nossos legisladores, e os nossos principais, que perfeitamente compreendem sua alta missão a êste respeito, missão prescrita pela Divindade, criando o Homem à sua imagem, e dotando-o de inteligência.

Não me ocupo, pois, hoje, da necessidade de promover a instrução popular. Todos sabem que ela é o baluarte inexpugnável da ordem, a garantia mais forte da tranqüilidade pública, a companhia inseparável do progresso, da riqueza, e prosperidade nacional, é a pedra angular, sôbre que assentam os tronos dos príncipes, pais de seus povos, é a inimiga mais poderosa da tirania, a mãe carinhosa da liberdade: sem instrução, nenhum povo é feliz !

Importância do estudo do Direito Administrativo - $\mathrm{O}$ assunto, porém, de que trato é outro. E' uma instrução especial. Tenho por fim despertar, com as minhas palavras, a atenção pública sôbre a importância do estudo do direito público e administrativo. Não me proponho tratar da filosofia do direito.

Não responderei à sublime pergunta de KANT: Qu'est-ce que le draịt en sai? Não abusarei de vossa benevolência, Senhores, expondo as diversas acepçōes em que é tomada a palavia direito.

E' suficiente, para clareza do que tenho que dizer. notar com o celebér rimo DE GLPANDo, que, não sendo o homem sòmente admitido na sociedade universal do gênero humano, mas tomando o lugar que the compete pelo nascimento no seio de uma família, e essa fazendo parte de uma grande o vasta reunião de famílias, as quais constituem um estado ou um nação, desta importantíssima circunstância nascem relações, e interêsses, que de dia em dia se desenvolvem, e sempre proporcionalmente ao progresso da civilização.

Direito Privado e Direito Público - Estas relações, êstes interêsces, ora do cidadão para com o cidadão, ora do cidadão para ccm o Estado, dão arigem a dois grandes corpos de direito: um que tem por fim fixar o estado das pessoas, constituir as famílias, dar títulos à propriedade, regular suas transações, e contratos, presidir às suas desavenças para determinar quem tem razão, indicar as fórmulas, tôdas as vêzes que se tratar de garantir direitos reconhecidos, ou instituídos, prevenir as violações das leis, os erros, os crimes, por meio de disposições criminais, pondo dêste modo suficientemente abrigada a proprie-

* Nota da Red. : Devido ao seu menor interésse atual, forem omitidos alguns trechos do discurso acima transcrito, pronunciado pelo Conselheiro Montezuma, entäo presidente do Inctituto dos Advogados Brasileiros, em sessẽo geral de 7 de setembro de 1848 . 
dade, a vida, a liberdade, e a honra de cada um; outro que toma por objeto de suas divisóes a corpo inteiro da sociedade, estatui as instituições sôbre que êle deve repousar; assina ao cidadão o lugar que deve ocupar, a parte que na sociedade the pertence; governa as famílias, que, por assim dizer, se confundem na grande família nacional; indica o modo por que serão administrados os interêsses coletivos da sociedade, exigindo o menor sacrifício possível dos interêsses individuais, que não são de maneira alguma esquecidos, antes são contemplados com a soma indispensável de direitos, que constituem outras tantas garantias individuais, civis e politicas.

O 1. ${ }^{\circ}$, Senhores, como vós sabeis, é o direito privado, como chamam os jurisconsultos mais notáveis.

O $20^{\circ}$ é o direito público, administrativo. Suas disposições, seus preceitos, abraçam os princípios constitutivos do govêrno, as regras que determinam as atribuições do funcionário público, qualquer que seja sua categoria, ou hierarquia administrativa. E como os interêsses politicos !la sociedade, cegundo sàbiamente diz FoUCART, não podem andar separados dos seus interêsses materiais, porque em todo caso os primeiros vêm a ser verdadeiramente a garantia dos segundos; é evidente a importância do estudo a que me refiro, estudo que tem a mais íntima reliação com a direito natural, do qual dimana - direito público, com a única diferença que o $1 .^{\circ}$ ensina o que deve ser; o 2. , porém, considera as instituições existentes um fato, e as explica', tanto pelo que concerne ao seu sentido literal, como ao seu espírito, seguindo-as ponto por ponto em sua aplicação habitual.

Jus privatum, disse BACON, sub tutella juris publici latet. E na verdade, é do direito público que toma a sua base o direito privado. Examine-se uma por uma as disposiçōes de direito, civil e criminal, e ver-se-á que, conquanto pareça que êste não se ocupa senão das pessoas, e da propriedade, da prevenção dos crimes e da proteção da sociedade, todavia, não só tôdas as suas medidas têm por fim o interêsse geral; mas ainda é do direito público que dimanam tôdas essas garantias, de que goza o cidadão, mais ou menos amplas, segundo o sistema de govêrno adotado.

Senhores, é já de sua natureza puro e elevado o sentimento que penetra no coração do homem aplicado ao estudo das leis, sentindo que em tudo se confunde com o culto da virtude, e o fortifica, para exprimir-se ainda com uma -legante frase do sábio publicista já citado.

Com o estudo, porém, do direito público e administrativo, além das idéias do bom e do justo, aprenđé-se sua utfldađe prática, comperetra-se o cictaitão de sua própria dignidade, familiariza-se com as questóes que fazem da política uma ciência difícil e talvez conjetural, aprende a avaliar os atos da administração, comparando-os com as leis fundamentais do Estado, torna-se o amigo sincero de seus deveres, ama finalmente o país, não tanto porque nasceu nêle; mas muito principalmente pelos direitos que goza, e a parte que the é dado tomar na pública administração. Se a legislação civil nos ensina e prega a honestidade, a justiça rigorosa, a franqueza, a dedicação para tudo que interessa o país e os nossos concidadãos, funda o patriotismo em fim.

Nem êste estudo é novo, Senhores, nem o direito público e administrativo é menos uma ciência. Isto poderia ser objeto de dúvida há trinta anos, quando pela primeira vez foi criada na Faculdade de Direito em França esta cadeira. Mas ainda nessa época sustentou o ilustre professor nomeado, que ela era menos nova, do que parecia. Já nessa época demonstrơ êle que a ciência tinha já suas fontes e suas autoridades. Dela se havia já ocupado grande número de escritores e de jurisconsultos.

Se isto era então, que diremos hoje, que tantas obras existem de direito público e administrativo, hoje que na França ilustrada, na França, filha que- 
rida da civilização, se faz dêste estudo um dọ mais indispensáveis, não só ao homem público, como ao cidadão, cuja posição o pode chamar a exercer empregos no país?

Faça o govêrno que não seja rara a leitura dos LAFERrIÈres, dos CoRMENINs, dos Foucarts, dos Macarels, dos LAFfons de LAdebat, Magnitots, e Huard Delamares, e sobretudo do célebre e profundo DE Gerando, cujos "Institutos de Direito Administrativo Francês", além de serem riquíssimo tesouro de bons princípios, podem servir de modêlo a qualquer obra djo mesmo gênero. Que o corpo da nação, dado a semelhante estudo, perfeitamente o entenda, e diàriamente se habilite a formar um sistema de suas máximas e regras, que thes sirva na avaliação dos atos administrativos da cabeça do Estado, o govêrno.

Hoje aprenderemos nos escritores estrangeiros a ciência da administração. E' comparando o que êles dizem relativamente ao seu país, e as leis que nêle vigoram, com o que determina a nossa legislação e ordenam os nossos poderes nistrativas, e descortinamos os remédios com que devemos satisfazê-las.

Amanhã também escreveremos; também analisaremos o nosso Estado político, e confirmaremos, ou corrigiremos as erros dos nossos mestres,

Senhores, é êsse estudo sublime, são suas inspirações científicas, que portenteiam os vicios, e as belezas, as lacunas, as incourências, os entos e as verdades do sistema político adotado pela nação. Nêle encontra o cidadão, amigo do seu país, os argumentos mais poderosos, e concludentes para combater as teorias exageradas, e as utopias perniciosas, inimigas de todo o bem, e grandeza social.

As alicantinas do ambicioso, os pérfidos queixumes das facções, suas sedutoras declamações de fingido patriotiomo, só êle descobre, đonfunde, e profliga.

Leges sacratissimo et quoe constringunt hominum vitae, intelligi ab omnibus debent.

Ignorante a grande maioria do povo de tudo que é relativo à administração do Estado, torna-se indiferente à sua sorte, não toma parte na solução das questöes mais graves, e transcendentes, em que o país pode achar-se empenhado; como adverte Brougham na sua valiosíssima obra Political Phylosophy, à imitação do povo Romano na época do domínio oligárquico dos patrícios, apenas se interessa em as questöes, que o afetam imediatamente, e cujo caráter é todo individual, tal a do monopólio das terras, ou dos vexames, violências, atrocidadies, praticadas pelos credores contra os devedores plebeus.

A Constituição e as leis ordinárias - Onde, senão no estudo do direito público e administrativo, se achará o seu conhecimento, a explicação exata, e científica do pacto social, texto fecundo, atual, e futuro de todos os nossos direitos, e de todos os nossos deveres? E' só meditando sèriamente em suas máximas, que se pode fazer idéia clara e precisa do nexo, a harmonia de nossas instituições políticas, paládio venerando de cuja conservação depende a felicidade da grande associação brasileira.

Vós sabeis que a lei civil e criminal é uma imediata emanação da Constituição, é o seu legítimo e natural comentário, é auréola, como a chamou um sábio, do pacto social. Tanto uma como outra é compreendida no estudo que preconizo, mas não para mostrar seus efeitos relativamente aos objetos sôbre que versam; mas sim para conhecer suas relaçóes gerais, como o motor que preside à ação das diversas autoridades sociais. Uma e outra é analisada, a fim de descobrir-se em que consiste a harmonia dos poderes, que concorrem para sua execução. 
Se a Constituição é a fonte de tôda a legislação, assim como o é de todo bem social, se o estudo, a análise da Constituição faz a base do estudo do direito público e administrativo, a êste pertence também encarar todos os poderes políticos do Estado pelo que respeita a suas relações com as instituições sociais. O poder judicial, portanto, encarregado da execução estrita e rigorosa das leis imperativas, não pade deixar de ser apreciado em os elementos, que o compõem na escola hierárquica das jurisdições, em que está distribuído, na organização, enfim, que lhe é própria.

O Poder Executivo - Senhores, falemos, agora, do poder executivo. Êle é o administrador, prò̀priamente dito, do país. E' de mister, pois, estudá-lo em suas relações com a lei, com o interêşe público, e com as garantias individuais do cidadão. $\mathbf{E}^{\prime}$ dêste estudo que devem resultar as regras e princípios do código administrativo nacional, regras, Senhores, que são tão diversas, quanto são diversos os objetos sôbre que recaem, e diversas as atribuições do poder a que me refiro.

Plara vas fazer ver ainda mais claramente a importância do assunto, com que julguei dever ocupar hoje a vossa atenção, peço-vos, Senhores, que reflitais um instante na grande vantagem que resulta para o país de conhecer quando a administração se deve considerar no seu modo de obrar discricionária, deliberativa, ou contenciosa. Que dúvidas importantes não se solverão? Quão terríveis, custosas, e perseguidoras contestaçōes não serão evitadas? Que dificuldades não serão suplantadas em benefício da indústria e da riqueza nacional, que depende sempre da formação, e acumulação da riqueza particular.

Em um simples discurso como êste, não é possível dizer muito; mas o objeto é tal, que não posso eximir-me de demorar-me nêle alguns instantes. Quais as regras que se devem adotar a êste respeito?

Administração discricionária - A administração se deve entender discricionária sempre que é graciosa, espontânea no exercício de suas atribuiçõos? Esta regra não sofre modificação quando procede segundo regras positivas, quando escolhe, vela, ordena, ou pronuncia? Eis o que o estudo do direito público e administrativo esclarecerá. E' deliberativa quando consulta, e resolve questões de interêsse geral, ou local, quando faz regulamentos, ou quando se limita a aprovar, autorizar, e exercer simples tutela pública? 0 art 102 da Constituição parece que assim 'o preceitua. E' finalmente contenciosa sempre que discute os litígios provenientes do encontro dos direitos particulares com $o$ interêsse público? Este princípio não fere de morte a independência do Poder Judiciário, e sua divisão? Não se verifica, então, como pretendia o douto Silvestre PinHeIRo FERREIRA, o monstruoso abuso de serem juízes aquêles mesmos que são partes na causa? Se tais litígios versam sôbre obrigaçóes nascidas de contratos civis, se a legislação não pode ser uma e a mesma para todo o país, fundada, como cumpre, nos princípios eternos de justiça universal, porque não exercerá o poder judiciário suas constitucionais atribuições, aplicando a lei ao fato nas questões e pendências entre os interêsses particulares e os interêsses gerais?

E' para proteger o cidadão nás questões com o fisco que foi criado êste privilégio? $E$ ' para tornar mais independente o juiz especial que se criou um fôro privilegiado? $E$ ' para tornar mais independente o juiz no julgamento de tais questões, que se deu um juiz especial, que se criou um fôro privilegiado? Não seriam imparciais, e ditadas ùnicamente pela justiça, as decisóes tomadas no fôro comum? Para que lado penderia a balança, em favor do povo, ou em favor do fisco? $E$ se se receia que os juizes no fôro comum sejam favoráveis aos interêsses particulares contra o fisco, por que não acontecerá o 
mesmo no fồro privilegiado? Qual a influência que deve produzir êste resultado? E' constitucional, é legítima, é moral, uma tal influência? Não transplantará ela os limites da imparcialidade em favor do fisco? Não cometerá abusos, e injustiças, para agradar ao fisco e satisfazer suas injustas pretensóes? Tôdas estas questóes devem ser sèriamente examinadas.

Hierarquia administrativa - Quais são os princípios que regulam a hierarquia administrativa? Alguma coisa existe em nossas leis, a êste respeito, mas tão confusamente, ou tão fora do alcance de todos, que por si mesma se faz digna de meditação; não tanto para trazer à luz do dia disposições obsoletas; mas para examinar os princípios em que tais disposições se baseiam, e ver se tais princípios estão de acôrdo com a Constituição do Estado.

A hierarquia administrativa principia no Imperador, e desce até o último empregado do poder administrativo. A Constituição, no ant. 102, declara o Imperador chefe do poder executivo, ou administrativo, e diz expressamente que êle o exercita pelos seus ministros. Êstes, no art. 133, são responsáveis, no que é a Constituição coerente, visto que o art. 99 reconhece a pessoa do Imperador inviolável e sagrada; nunca sujeita a responsabilidade alguma.

Entre nós, pois, o Imperador reina, e governa, à vista da lei fundamental do país, que sábia e previdente resolveu essa questão, que tanto alimento deu na França ao espírito de partido, se não faccioso.

Entre nós o monarca reina e governa! A nação não quis reduzir o Chefe do Estado à triste oruel posição de ver o mal e o não poder remediar, senão com a demissão dos ministros, o que nem sempre é conveniente, e que deve ser sempre considerado como uma medida extrema.

Criando a Constituição um quarto poder, que denominou a chave de tôda a organização política, encarregado de velar sôbre a manutenção da independência, equilíbrio, e harmonia dos mais poderes, e delegando-o ao Imperador, como chefe supremo da nação, seria a mais flagrante contradição privar a mação de influência sempre benéfica, que se não pode jamais presumir hostil, de sua sabedoria no govêrno do Estado.

Entre nós o monarca reina, e governa! $E^{\prime}$ a maior garantia que a Constituição poderia consagrar! E' a maior garantia que pode ter a ordem pública, a prosperidade, a honra, e a glória nacional, perfeitamente simbolizadas na pessoa augusta daque'e a quem a lei fundamental reconhece a fonte de todo bem, o complexo de tôdas as virtudes sociais, o emblema majestoso da sabedoria nacional, o primeiro brasileiro, o brasileiro por excelência!

Mas é necessário que a administração geral saia dêste centro de atividade, e de patriotismo, e que se derrame por todos os pontos da periferia do vasto círculo administrativo. E' então que convém estudar as diversas categorias administrativas, formando, como diz LAFERRIìre, o ministro (e é o mesmo entre nós.) o $20^{\circ}$ degrau da escala. O conselho dos ministros é o representante ¿a ação administrativa responsável: cada ministro em particular representa o ramo administrativo, que lhe é confiado.

Pode haver um presidente do conselho à vista do nosso pacto social? Se se resolver esta importantíssima questão afirmativamente, quais devem ser as atribuiçóes que o distingam dos outros ministros? Podem elas ter reforência às atribuições conferidas pela letra, e pelo espírito da constituição ao chefe do poder executivo? Pode o monarca delegar a um súdito seu tais atribuiçóes? Pode fazê-lo a um corpo qualquer no Estado? A tôdas estas questões respondo desde já negativamente. Mas tudo isto trouxe à vossa consideração em apoio e sustentaça do que tenho dito acêrca da importância, verdadeiramente vital, do estudo do direito público e administrativo. 
Era ocasiâo, Senhores, de tratar de todos os conselhos subsidiários, e auxiliares da ação governativa; principiando pelo conselho do Estado; e então reentraria em algumas considerações relativas à sua organização e atribuiçōes.

$\mathbf{O}$ conselho supremo militar, as secretarias de Estado, as municipalidades, e outros estabelecimentos públicos, que prestam ao país relevantíssimos serviços, ajudando o poder administrativo na laboriosíssima espinhosa tarefa, que the confiara a lei, também fazem o objeto do estudo de cuja utilidade me ocupo. Mas o espaço me falta para tratar de todos.

Mencionei, Senhores, as municipalidades, e com razão; pois nenhuma corporação no Estado, das que se podem considerar subalternas, é mais importante, e deve merecer maior atenção para ser estudada.

As municipalidades em tôda parte são consideradas elementos políticos da organização social; e debaixo dêste ponto de vista suas relações são diretas com o govêrno supremo do país, com seus imediatos delegados. Se não consideradas como indivíduos, as municipalidades têm bens próprios que administram em comum, de que gozam, e com o que muito concorrem para s felicidade e paz geral.

Quão vasto não é o estudo dos estabelecimentos morais e universais, como os chama o Barão de Gerando? A educação, e instrução pública, que cuidados não devem merecer à autoridade administrativa? Chamai, embora, êsses cuidados, intervenção: eu também os chamarei assim; mas essa intervenção faz uma parte especial de seus mais explícitos e rigorosos deveres, atenta a fonte de que dimanam.

A aliança, Senhores, contraída entre a educação, a moral e a religião, me obriga a lembrar-vos neste lugar que nenhum princípio mais reclama o estudo do direito público e administrativo do que o princípio religioso, porque nenhum ganhará mais do que êle. Os estabelecimentos religiosos reclamam entre nós apoio e desenvolvimento. O clero reciama garantias e consideração social. A igreja brasileira reclama do govêrno uma fundação estável digna da nação e do século em que vivemos.

Não basta dizer que a autoridade civil é independente da autoridade eclesiástica; que um fôro é distinto, completamente independente, do outro; mas é preciso adotar medidas, estabelecer os meios, formar convenções, que tornem efetiva e fácil essa independência, sem violência, sem o menor vexame, sem detrimento da causa pública, sem prejuízo, enfim, da liberdade de consciência, direito sactatíssimo do homem! $E$ ' mister também que uma outra autoridade tenha ação sôbre o clero, em todos os graus da hierarquia eclesiástica: é mister convencionar sôbre as insțâncias superiores no fôro espiritual. A êste respeito há tudo a fazer : e só o estudo, a que me refiro, pode derramar luz sôbre a praticabilidade do assunto. Enfim, os direitos da igreja brasileira não podem ser mais nem menos do que são os direitos comuns e universais de tôdas as igrejas católicas do universo.

Mr. DuRAND DE MAILlaNe na sua vasta e doutíssima obra intitulada As liberdades da Igreja Galicana, publicada em 1771, diz:

"Rien de si familier parmi nous que le nom de libertés de I'Eglise Gallicane, rien aussi de plus important! Il est dangereux d'en parler ou d'en écrire sans les bien connaître, et peu de personnes en son instruites".

Se na ilustrada França, se na França eminentemente católica, ainda mais na época em que aquêle ilustre escritor deu à luz a sua obra, conquanto todos falassem nas liberdades da Igreja dos BossueTs e dos FENELIONS, poucas pessoas as conheciam bem, poucos espíritos as entendiam convenientemente; se ainda hoje, talvez, nesse país clássico do direito público e administrativo, poucos escritores (não direi poucas pessoas) enunciam-se sôbre tal assunto de modo que infundam em seus leitores a convicção de que possuem um profundo 
saber sôbre o objeto: que diremos, Senhores, em referência ao nosso país, onde o próprio govêrno, e os próprios representantes da nação, ainda nem ao menos encetararn a questão? Onde tudo está por fazer? Em uma igreja onde não há doutores? Em um país em cujas academias se não professam estudos especiais, e relativos aos dogmas da Igreja? Senhores, é já tempo de aliviar a vossa atenção da fadiga que deve causar um assunto mal e superficialmente tratado, sendo aliás da primeira e mais elevada transcedência.

Criação da cadeira de Direito Administrativo - Terminarei, Senhores, dizeñu que, se o assunto ê vasto e importantíssimo, também são grandes as dificuldades que devem embaraçar o seu desenvolvimento: mas cumpre começar. Faço votos, portanto, para que o govêrno do Imperador, de acôrdo com a assembléia legislativa, crie uma cadeira de direito público e administrativo aqui na Côrte, ou onde em sua sabedoria mais conveniente julgar. Façamos votos, Senhores, para que êste ramo do nosso direito seja ensinado, e direi mesmo vulgarizado.

Antes de Brougham, provou Hume - que a politica, isto é, êste ramo das ciências morais, que trata da formação das associações políticas, e da estrutura dos governos, que tem por base a história, o estudo aprofundado das condiçōes primordiais dos povos, seus hábitos universalmente reconhecidos, que contempla o desenvolvimento da grandeza das nações, a marcha de sua civilização, sua decadência, suas instituiçôes, seus códigos, seus tratados, suas guerras, suas comoções intestinas, a gerência enfim doméstica e internacional de seu negócios; a política, fundando-se na observação, e experiência de tudo que tem relação com a vida física, moral, religiosa, e administrativa das naçōes, é uma ciência cujos preceitos são da mais alta transcendência. Quantó, p-rém, não perderia de sua importância, o utilidade, o estudo dêste fecundissimo ramo dos conhecimentos humanos, se o direito público e administrativo não se encarregasse de fazer aplicação de suas máximas; se as verdades sublimes, que dela resultam, não fôssem pelo estudo, de que me tenho hoje ocupado, oferecidas aos povos, como outros tantos faróis, que os têm de guiar, e aos seus respectivos governos, por enitre os abrolhos, e em meio das tempestades da vida política? 